\title{
Synthesis and Modification of Novel Iminecalix[4]arene Derivatives
}

\author{
Satish Balasaheb Nimse, Junbae Kim, Jeong Tae Lee, Keum-Soo Song, ${ }^{\dagger}$ Junghoon Kim, ${ }^{\dagger}$ \\ Van-Thao Ta, Van-Thuan Nguyen and Taisun Kim* \\ Institute for Applied Chemistry and Department of Chemistry, Hallym University, Chuncheon 200-702, Korea \\ ${ }^{*}$ E-mail: tskim@hallym.ac.kr \\ ${ }^{\dagger}$ Biometrix Technology, Inc. 202 BioVenture Plaza, Chuncheon 200-161, Korea \\ Received October 19, 2010, Accepted January 27, 2011
}

\begin{abstract}
The synthesis of novel iminecalix[4]arenes and further modification thereafter is described using a synthetic strategy. The reaction of the benzaldehyde derivatives with tetraamine functions on the calix[4]arene easily afforded the pure compounds in $92.4-95.7 \%$ yields, regardless of the effect of the substituents on the benzaldehyde derivatives. These compounds were stable under the conditions to obtain their analogue dialkylated in the narrow rim, with $83.2-89.9 \%$ yields. Characterization of the newly synthesized iminecalix[4]arene derivatives by spectroscopic methods revealed that all compounds are in the cone conformations.
\end{abstract}

Key Words : Supramolecular chemistry, Calixarenes, Imines, Receptors, Spectroscopy, Substituent effects

Many macrocyclic compounds have been developed for mimicking several biological processes. Calix[4]arene, one of the noted supramolecular assembly, ${ }^{1-3}$ provides a unique cavity capable of recognizing and confining various guest molecules. ${ }^{4,5}$

In search of the deep-cavity calix[4]arenes, researchers had developed the wide and narrow rim modified derivatives. ${ }^{6-10}$ One of the approach used was to substitute the wide rim of the calix[4]arene with the Schiff bases. The selective functionalization of the wide rim of the calix[4]arene keeping the narrow rim free for further modifications is very important in the calixarene chemistry. In spite of attempts to substitute the wide rim of the calix[4]arene selectively with tetra Schiff base functions, few research groups had synthesized calix[4] arene with mono or di Schiff base functions. ${ }^{11}$ The synthesis of the tetra substituted calix[4]arene Schiff base derivatives was possible only by using the formyl calix[4]arenes or calix[4]arenes pre-alkylated at the narrow rim as precursors. ${ }^{12}$ These methods employed calix[4]arenes pre-substituted at the narrow rim, hence the molecules obtained were not feasible for further modifications. ${ }^{13}$

The selective modification of the wide rim of the calix[4]arene with tetra imine functions keeping the narrow rim free for further modifications has been never reported. Herein, we report a high yielding and expedient avenue to synthesize a series of new iminecalix[4] arene derivatives. The 5,11,17,23-tetrakis(amine)-25,26,27,28-tetrahydroxycalix[4]arene $\mathbf{1}$ as depicted in Scheme 1 was used as a precursor. $^{14,15}$

As shown in Scheme 1, the reaction of $\mathbf{1}$ with benzaldehyde derivatives in acetonitrile at room temperature afforded iminecalix[4]arene derivatives 2a-2d with 92.4$95.7 \%$ yields (see the Supplementary Information). This way, the generation of deep cavity and the introduction of tetra imine functions on the wide rim of calix[4]arene happened concomitantly in a one-step process.

The selective modification of the narrow rim, gives flexibility to the calix[4]arene architecture. ${ }^{16}$ Therefore, it was

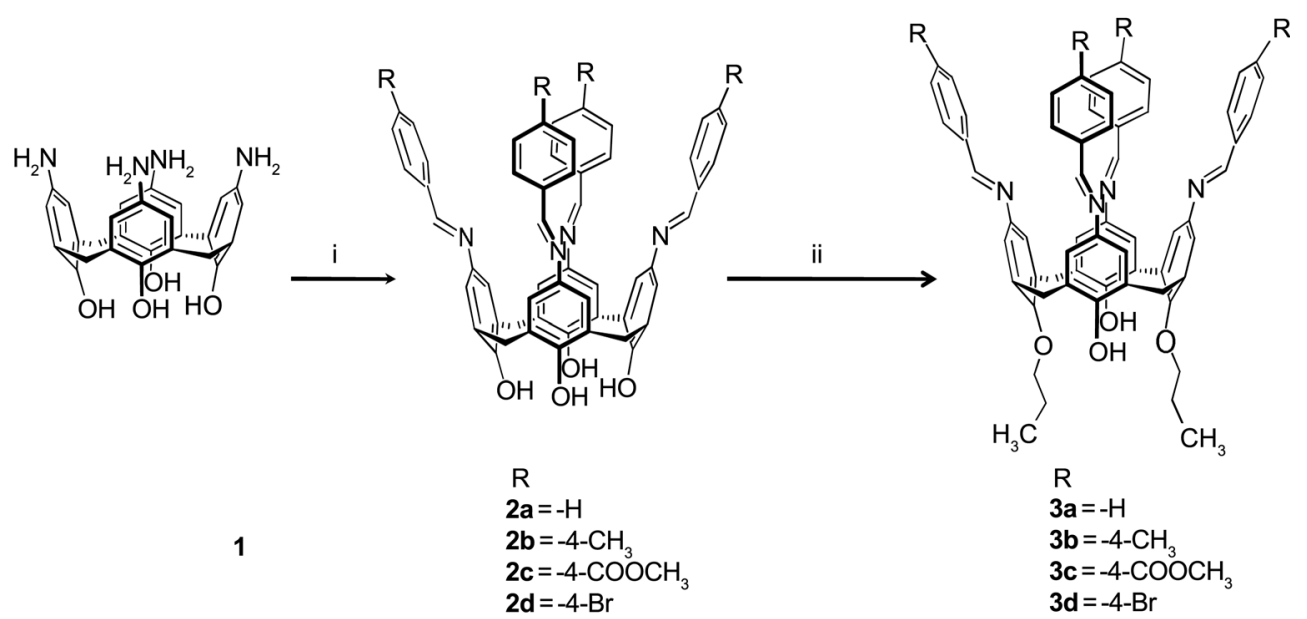

Scheme 1. Reagents and conditions: (i) R-Ph-CHO, $\mathrm{CH}_{3} \mathrm{CN}, \mathrm{N}_{2}, 2$ h, 92.4-95.7\% (ii) $\mathrm{Br}_{-} \mathrm{CH}_{2} \mathrm{CH}_{2} \mathrm{CH}_{3}, \mathrm{~K}_{2} \mathrm{CO}_{3}, \mathrm{CH}_{3} \mathrm{CN}, \mathrm{N}_{2}$, reflux, 12 h, $83.2-89.9 \%$. 


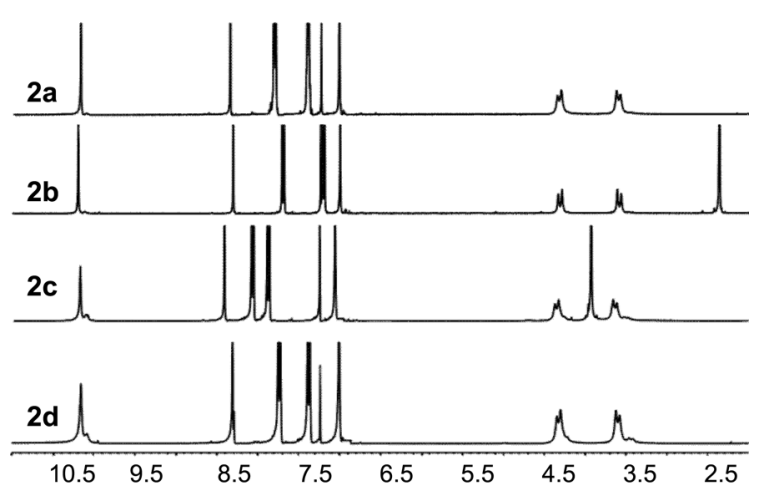

Figure 1. Partial ${ }^{1} \mathrm{H}$ NMR $\left(\mathrm{CDCl}_{3}\right.$ at $\left.298 \mathrm{~K}\right)$ spectra of compounds 2a-2d.

interesting to modify compounds $\mathbf{2 a - 2 d}$ to their analogues dialkylated in the narrow rim. The synthesis of the target compounds 3a-3d is depicted in Scheme 1. The exchange of proton on distal hydroxyl groups for a propyl function in the reaction of $\mathbf{2 a - 2 d}$ with 1-bromopropane in the presence of excess $\mathrm{K}_{2} \mathrm{CO}_{3}$ gave the desired dialkylated compounds 3a3d in $83.2-89.9 \%$ yield (see the Supplementary Information). According to the literature, it was presumed that imine bonds are quite unstable. ${ }^{17}$ However, we found that, all iminecalix[4]arene derivatives $\mathbf{2 a - 2 d}$ were stable and successfully converted to their dialkylated analogues following the method described here.

Newly synthesized compounds, as shown in Scheme 1 were characterized by the analysis of their ${ }^{1} \mathrm{H}$ NMR and ${ }^{13} \mathrm{C}$ NMR and MALDI-TOF spectra. For example, the ${ }^{1} \mathrm{H}$ NMR spectra of 2a showed a typical AB pattern for the methylene bridge protons represented by the two pairs of doublets at $\delta$ 3.63 and $\delta 4.31 \mathrm{ppm}$ for the axial and equatorial protons, respectively. The ${ }^{1} \mathrm{H}$ NMR spectrums of the compounds $\mathbf{2} \mathbf{b}$ 2d showed a similar pattern. As shown in Table 1, the signal for imine protons in 2a appeared at $\delta 8.30 \mathrm{ppm}$ in ${ }^{1} \mathrm{H} \mathrm{NMR}$ and imine carobons were appeared at $\delta 157.8 \mathrm{ppm}$ in ${ }^{13} \mathrm{C}$ NMR, revealing the formation of the iminecalix[4]arene.

The tetra substitution in the compound $\mathbf{2 a}$ was confirmed from the close observation of the ${ }^{1} \mathrm{H}$ NMR signals for the $\operatorname{Ar}-\mathrm{OH}(\delta 10.15 \mathrm{ppm}),-\mathrm{HC}=\mathrm{N}-(\delta 8.30 \mathrm{ppm})$, calixarene Ar$\mathrm{H}(\delta 7.00 \mathrm{ppm})$, and a pair of doublets for the $\mathrm{Ar}-\mathrm{CH}_{2}-\mathrm{Ar}(\delta$
4.30, and $\delta 3.60 \mathrm{ppm}$ ), respectively in a ratio of $1: 1: 2: 1: 1$. From the ${ }^{1} \mathrm{H}$ NMR spectra of $\mathbf{2 a}$, the integration pattern for above mentioned protons was found to be $4 \mathrm{H}: 4 \mathrm{H}: 8 \mathrm{H}: 4 \mathrm{H}$ : $4 \mathrm{H}$, indicating the successful tetra substitution. Similar patterns of the ${ }^{1} \mathrm{H}$ NMR signals were found in case of compounds $\mathbf{2 b - 2 d}$ (Figure 1). The tetra substitution was also confirmed from the integration of the ${ }^{1} \mathrm{H}$ NMR signal for 20 aromatic protons, which appeared at $\delta$ 7.82-7.78, 7.40-7.38 ppm in compound 2a, while compounds $\mathbf{2 b - 2 d}$ showed relevant signals for 16 aromatic protons in their respective ${ }^{1} \mathrm{H}$ NMR spectra.

Figure 1 and Scheme 1 illustrates that the imine[4]calixarene can be successfully obtained by the reaction of aminecalix[4]arene 1 and benzaldehyde derivatives, irrespective of the electron-donating or electron-withdrawing substituent's on the benzaldehyde moiety. Using benzaldehyde and $p$ tolualdehyde compounds $\mathbf{2 a}$ and $\mathbf{2 b}$ were obtained with the yields of $95.7 \%$ and $94.7 \%$, respectively. Whereas, using methyl 4-formylbenzoate and 4-bromobenzaldehyde, the compounds $\mathbf{2 c}$ and $\mathbf{2 d}$ were obtained with good yields of 93.3 and $92.4 \%$, respectively.

It is also important to notice that without any extra purification step, the excess of benzaldehyde was completely removed by the addition of $n$-hexane in the reaction mixture

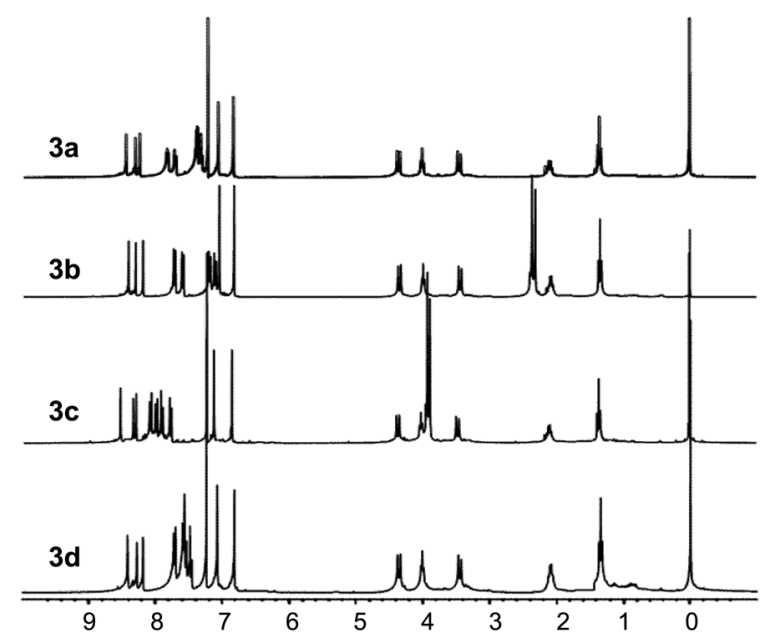

Figure 2. Partial ${ }^{1} \mathrm{H}$ NMR $\left(\mathrm{CDCl}_{3}\right.$ at $\left.298 \mathrm{~K}\right)$ spectra of compounds 3a-3d.

Table 1. Yields and spectral data of iminecalix[4]arene derivatives

\begin{tabular}{|c|c|c|c|c|c|c|}
\hline Compounds & $\begin{array}{c}\Delta \delta \text { ppm } \\
\left({ }^{1} \mathrm{H} \text { NMR }\right) \\
\left(\mathrm{Ar}-\mathrm{CH}_{\mathrm{a}} \mathrm{H}_{\mathrm{e}}-\mathrm{Ar}\right)\end{array}$ & $\begin{array}{c}\text { sppm } \\
\left({ }^{13} \mathrm{C} \mathrm{NMR}\right) \\
\left(\mathrm{Ar}-\mathrm{CH}_{2}-\mathrm{Ar}\right)\end{array}$ & $\begin{array}{c}\text { Sppm } \\
\left({ }^{1} \mathrm{H} \text { NMR }\right) \\
(\mathrm{Ar}-\mathrm{H})\end{array}$ & $\begin{array}{c}\text { Sppm } \\
\left({ }^{1} \mathrm{H} \text { NMR }\right) \\
(-\mathrm{CH}=\mathrm{N}-)\end{array}$ & $\begin{array}{c}\delta p p m \\
\left({ }^{13} \mathrm{C} \text { NMR }\right) \\
(-\mathrm{CH}=\mathrm{N}-)\end{array}$ & $\%$ yield \\
\hline $2 \mathbf{a}$ & 0.76 & 32.47 & 7.01 & 8.34 & 159.3 & 95.7 \\
\hline $2 \mathbf{b}$ & 0.72 & 32.48 & 7.00 & 8.31 & 159.2 & 94.7 \\
\hline $2 \mathrm{c}$ & 0.73 & 32.39 & 7.05 & 8.41 & 157.8 & 93.3 \\
\hline 2d & 0.72 & 32.41 & 7.00 & 8.30 & 157.7 & 92.4 \\
\hline $3 \mathbf{a}$ & 0.91 & 32.10 & $6.86,7.09$ & $8.47,8.33$ & $159.9,157.3$ & 89.9 \\
\hline $3 \mathbf{b}$ & 0.91 & 32.17 & $6.84,7.06$ & $8.43,8.32$ & $159.9,157.4$ & 88.1 \\
\hline $3 c$ & 0.91 & 32.05 & $6.86,7.13$ & $8.54,8.31$ & $156.6,155.7$ & 83.2 \\
\hline 3d & 0.91 & 32.10 & $6.82,7.08$ & $8.42,8.20$ & $158.5,155.8$ & 86.5 \\
\hline
\end{tabular}

a- axial proton, e- equatorial proton 
while isolating the final compounds $\mathbf{2 a - 2 d}$. The complete removal of benzaldehyde is indicated by the absence of aldehyde peak at $\delta 9.90-10.10 \mathrm{ppm}$ in the respective ${ }^{1} \mathrm{H}$ NMR spectra of compounds $\mathbf{2 a - 2 d}$. Hence, the tetra substituted compounds $\mathbf{2 a - 2 d}$ were obtained easily keeping the narrow rim hydroxyl groups free for further modifications. The alkylation of the narrow rim hydroxyl groups on the distal positions in the compounds 2 a-2d gave compounds 3a-3d.

Analysis of the ${ }^{1} \mathrm{H}$ and ${ }^{13} \mathrm{C}$ NMR spectra of the narrow rim modified compound 3a, established the alkylation of hydroxyl groups in distal positions. Similar to that of the compound $\mathbf{2 a}$, compound $\mathbf{3 a}$ also showed the typical AB pattern for the methylene bridge protons represented by two pairs of doublets at $\delta 3.35$ and $\delta 4.35 \mathrm{ppm}$ for the axial and equatorial protons, respectively.

As shown in the Figure 2 and Table 1, the singlet's for the imine protons and the calix[4]arene aromatic protons in the compound 2a were split into the two pair of singlet's, each for the imine protons and the calix[4] arene aromatic protons after the $o$-alkylation to obtain the compound 3a. Moreover, phenyl aromatic protons also followed the trend. The bridging of the aromatic rings by the imine bonds in the iminecalix[4]arene, results into a long $\pi$-electron conjugation system. The effect of this long $\pi$-electron conjugation is reflected in the ${ }^{1} \mathrm{H}$ NMR spectra of compound 3a. The signal for four imine protons in compound 3a, split's into two singlet's for two protons each, one due to the unsubstituted hydroxyl group and the other due to the substituted hydroxyl group at $\delta 8.47,8.33 \mathrm{ppm}$, respectively. As shown in the Table 1 , the ${ }^{13} \mathrm{C}$ NMR signals for four imine protons in compound 3a, split's into two singlet's for two protons each, one due to the unsubstituted hydroxyl group and the other due to the substituted hydroxyl group at $\delta 159.9,157.3 \mathrm{ppm}$, respectively. A marked upfield shift was observed for the protons of the unsubstituted hydroxyl groups. The signal for the four phenolic hydroxyl group protons at $\delta 10.15 \mathrm{ppm}$ in the compound 2a, was found to be shifted to $\delta 8.26 \mathrm{ppm}$ for two protons of the phenolic hydroxyl group in the compound 3a. Compounds 3b-3d also showed the similar patterns as compound 3a in their respective ${ }^{1} \mathrm{H}$ NMR and ${ }^{13} \mathrm{C}$ NMR spectra. It has now been established that analysis of ${ }^{1} \mathrm{H}$ NMR and ${ }^{13} \mathrm{C}$ NMR spectrums can be effectively employed for conformational analysis of calix[4]arenes. ${ }^{18}$ As shown in Table 1, the methylene bridge carbons in compounds $\mathbf{2 a - 2 d}$ and 3a-3d appeared between $\delta$ 32.48-32.39 ppm, which noticeably validated that all compounds are in the cone conformations.

In conclusion, we have shown that the new iminecalix[4] arenes with the cone conformation can be synthesized in high yield at room temperature. Our strategy has proven that the iminecalix[4]arenes with the narrow rim free for further modification can be easily obtained. The narrow rim hydroxyl groups of the iminecalix[4]arene derivatives were successfully dialkylated with high yields. The method used here is highly applicable to produce a series of various iminecalix[4]arenes and their narrow rim modified derivatives. The synthesis and application of the iminecalix[4]arene derivatives is under investigation.

Acknowledgments. This research was supported by the Hallym University Research Fund, 2010 (HRF-2010-019).

\section{References}

1. (a) Calixarenes: A Versatile Class of Macrocyclic Compounds; Vicens, J., Ed.; Kluwer Academic Publishers: Dordrecht, 1991. (b) Lohtak, P.; Zieba, R.; Hromadka, V.; Stibor, I.; Sykora, J. Tetrahedron Lett. 2003, 44, 4519.

2. Ikeda, A.; Shinkai, S. Chem. Rev. 1997, 97, 1713.

3. Bohmer, V. Angew. Chem. Int. Ed. Engl. 1995, 34, 713.

4. Gutsche, C. D. Calixarenes Revisited; The Royal Society of Chemistry: Cambridge, 1998.

5. (a) Antonisse, M. M. G.; Reinhoudt, D. N. Chem. Commun. 1998 443. (b) Sessler, J. L.; Camiolo, S.; Gale, P. A. Coord. Chem. Rev. 2003, 240, 17. (c) Boiocchi, M.; Del Boca, L.; Gomez, D. E.; Fabbrizzi, L.; Licchelli, M.; Monzani, E. J. Am. Chem. Soc. 2004, 126,16507

6. Gutsche, C. D.; Pagoria, P. F. J. Org. Chem. 1985, 50, 5795.

7. Atwood, J. L.; Orr, G. W.; Bott, S. G.; Robinson, K. D. Angew. Chem., Int. Ed. Engl. 1993, 32, 1093.

8. Makha, M.; Raston, C. L. Tetrahedron Lett. 2001, 42, 6215.

9. Kumar, S.; Chawla, H. M.; Varadarajan, R. Tetrahedron Lett. 2002, 43, 2495

10. (a) Miyaji, H.; Dudic, M.; Tucker, H. R.; Prokes, I.; Light, M. E.; Hursthouse, M. B.; Stibor, I.; Lhoták, P. Tetrahedron Lett. 2002, 43, 873. (b) Adruini, A.; Brindani, E.; Giorgi, G.; Pochini, A.; Secchi, A. Tetrahedron 2003, 59, 7587.

11. (a) Tamburini, S.; Tomasin, P.; Vigato, P. A.; Casnati, A.; Domiano, L. Inorganica Chimica Acta 1997, 254, 209. (b) Hwang, G. T.; Kim, B. H. Tetrahedron Lett. 2000, 41, 5917. (c) Alemi, A. A.; Shaabani, B.; Dilmaghani, K. A.; Ganjali, S. T. Molecules 2001, 6, 417.

12. (a) Guo, T.; Zheng, Q.; Yang, L.; Huang, Z. J. Incl. Phen. Macr. Chem. 2000, 36, 327. (b) Durmaz, M.; Alpaydin, S.; Sirit, A.; Yilmaz, M. Tetrahedron: Asymm. 2006, 17, 2322. (c) Liang, Z.; Liu, Z.; Gao, Y. Spectrochimica Acta Part A 2007, 68, 1231.

13. Klimentova, J.; Vojtíšek, P. J. Mol. Struct. 2007, 826, 48.

14. (a) Shinkai, S.; Tsubaki, T.; Sone, T.; Manabe, O. Tetrahedron Lett. 1985, 26, 3343. (b) Zhang, W. C.; Zheng, Y. S.; Huang, Z. T. Synth. Commun. 1997, 27, 3763. (c) Kumar, S.; Kurur, N. D.; Chawla, H. M.; Varadarajan, R. Synth. Commun. 2001, 31, 775.

15. (a) Wagenigen, A. M. A.; Snip, E.; Verboom, W.; Reinhoudt, D. N.; Boerrigter, H. Liebigs Ann/Recueil 1997, 2235. (b) Dudic, M.; Colombo, A.; Sansone, F.; Casnati, A.; Donofrio, G.; Ungaro, R. Tetrahedron 2004, 60, 11613.

16. Arduini, A.; McGregor, W. A.; Paganuzzi, D.; Pochini, A.; Secchi, A.; Ugozzoli, F.; Ungaro, R. J. Chem. Soc., Perkin Trans. 2 1996, 839.

17. Manabe, K.; Oyamada, H.; Sugita, K.; Kobayashi, S. J. Org. Chem. 1999, 64, 8054.

18. (a) Jaime, C.; Mendoza, J. D.; Prados, P.; Nieto, P. M.; Sanchez, C. J. Org. Chem. 1991, 56, 3372. (b) Shu, C. M.; Liu, W. C.; Ku, M. C.; Tang, F. S.; Yeh, M. L.; Lin, L. G. J. Org. Chem. 1994, 59, 3730. 